\title{
Relation between the longitudinal development of lipoprotein levels and biological parameters during adolescence and young adulthood in Amsterdam, The Netherlands
}

\author{
J W R Twisk, H C G Kemper, G J Mellenbergh, W van Mechelen
}

\begin{abstract}
Study objectives - To analyse the relation between the longitudinal development of total serum cholesterol (TC), high density lipoprotein cholesterol (HDL), and the TC/ HDL ratio and the longitudinal development of the biological parameters body fatness (SSF), lean body mass (LBM), and cardiopulmonary fitness $\left(\mathrm{VO}_{2}-\mathrm{max}\right)$. The relations were analysed with generalised estimating equations (GEE).
\end{abstract}

Setting - The relations were investigated with data from the Amsterdam growth and health study, a longitudinal study in which six measurements were carried out within a period of 15 years.

Participants - Altogether 98 females and 84 males aged 13 years at the start of the study.

Main results - Adjusted for lifestyle and other biological parameters, the longitudinal development of TC was inversely related to the development of LBM (standardised regression coefficient $\beta=-0.27$; $p \leq 0.01)$ and positively to SSF $\left(\beta_{\text {males }}=0.32\right.$; $p \leq 0.01$ and $\left.\beta_{\text {females }}=0.15 ; p \leq 0.01\right)$. HDL was inversely related to $L B M(\beta=-0.26$; $\mathrm{p} \leq 0.01)$ and positively to $\mathrm{VO}_{2}-\max (\beta=$ $0.08 ; p \leq 0.05)$. The TC/HDL ratio was positively related to $S S F\left(\beta_{\text {males }}=0.39 ; p \leq 0.01\right.$ and $\left.\beta_{\text {females }}=0.13 ; p \leq 0.01\right)$ and inversely to $\mathrm{VO}_{2}-\max (\beta=-0.09 ; p \leq 0.05)$.

Conclusions - The longitudinal analyses showed that body fatness was related to a high risk profile with respect to hypercholesterolaemia, and cardiopulmonary fitness to a low risk profile. Furthermore, it was shown that using body mass index as an indicator of body fatness in relation to lipoprotein values, has some important drawbacks.

\section{(f Epidemiol Community Health 1996;50:505-511)}

Because it is well known that the origin of atherosclerosis lies in early childhood, ${ }^{1}$ it is important to start prevention of atherosclerosis as soon in life as possible. Therefore risk factors regarding atherosclerosis, such as hypercholesterolaemia, obesity, and hypertension have to be identified at a young age. Early identification is only useful, however, if the predictability of early measurements of these risk factors for values later in life (ie, tracking analysis) has been assessed. If some degree of tracking is observed then one has to investigate which parameters influence the longitudinal development of these risk factors. In preventive strategies these influencing factors can than be manipulated in order to prevent the development of atherosclerosis later in life.

One of the most important risk factors for atherosclerosis is hypercholesterolaemia (ie, high values of total serum cholesterol (TC), low values of high density lipoprotein cholesterol (HDL), or (perhaps) more important, high values of the TC/HDL ratio. ${ }^{23}$ It is often shown that TC, HDL, or the TC/HDL ratio track well from childhood or adolescence into adulthood, ${ }^{4-6}$ indicating that influencing these parameters during adolescence or young adulthood can have important implications for the prevention of atherosclerosis later in life. Because of this, many studies have analysed the relation between TC, HDL, and/or the TC/ HDL ratio and potential influencing factors during these younger age periods. ${ }^{7-22}$

Potential parameters that influence the longitudinal development of lipoprotein values can be divided into biological and lifestyle factors. The latter consist of smoking, alcohol consumption, dietary intake, and daily physical activity. Relevant biological parameters are cardiopulmonary fitness and body weight (ie body fatness). However, lean body mass (LBM), another component of body weight, seems to be related to lipoprotein concentrations. ${ }^{2324}$ One problem is that most studies do not take into account the fact that biological and lifestyle parameters not only influence lipoprotein values, but also each other (eg, increasing daily physical activity enhances cardiopulmonary fitness, which influences body fatness or the inverse relation between smoking behaviour and body fatness, etc). Thus, analysis of the relation between the longitudinal development of lipoprotein concentrations and biological parameters has to be investigated correcting for relevant lifestyle parameters. In this paper we correct for dietary intake, smoking behaviour, alcohol consumption, and daily physical activity.

Another problem with studies investigating the relation between lipoprotein levels and biological parameters is that most of them have a cross sectional design, ${ }^{7101215-22}$ which limits the interpretation of the results. The few longitudinal studies investigating this problem are either experimental ${ }^{2324}$ or observational..$^{8111314}$ 
The results of the observational studies have limitations, however, because measurements at only two points in time are used in the analysis. In these studies the relation between changes in lipoprotein levels and changes in biological parameters, where change is defined as the difference between two measurements, is investigated. In this paper the relation between lipoprotein concentrations and relevant biological parameters is investigated longitudinally, not using two points in time but all the available longitudinal data. The data are derived from the Amsterdam growth and health study, which includes six longitudinal measurements between 13 and 27 years of age.

A comparison is made between univariate analyses, in which the influences of the biological parameters are investigated separately, and multivariate analyses in which the relation between the development of the lipoprotein concentrations and biological parameters is investigated correcting for relevant lifestyle parameters.

\section{Methods \\ STUDY POPULATION}

The Amsterdam growth and health study is a longitudinal study which started in 1977 with 307 subjects ( 148 males and 159 females) from the first and second forms of a secondary school in Amsterdam. At the start of the study the mean (SD) age of both the boys and the girls was 13.0 (0.8) years. From 1977 onwards four annual measurements were carried out. Altogether 233 subjects (102 males and $131 \mathrm{fe}-$ males) completed these four measurements. In 1985,200 subjects returned to the laboratory for a fifth measurement and in 1991, 181 subjects were measured for the sixth time. The population used in this study consisted of these 181 subjects. The total number of missing observations in this population over all longitudinal measurements was about $2 \%$. At the last measurement, in 1991, the mean age of both the males and females was 27.1 (0.8) years. For the variables of interest in this study, no drop-out effects were observed during the longitudinal period. ${ }^{25}$

\section{LIPOPROTEINS}

For the determination of TC and HDL, approximately $10 \mathrm{ml}$ of venous blood were taken from the vena antecubitis with a vacutainer. Non-fasting TC and HDL were assayed using standard methods. ${ }^{26-28}$ Because the longitudinal development of TC, HDL, and the TC/HDL ratio is different for males and females, and because it is influenced by biological maturity, ${ }^{2529}$ it should be analysed correcting for time, gender, and biological maturity. In this study we determined biological maturity up to age 16 using skeletal age from annual radiographs. ${ }^{30}$ For older ages we used actual chronological age.

\section{BIOLOGICAL PARAMETERS}

Body fatness was quantified as the sum of the bicipital, tricipital, subscapular, and suprailiac skinfold thickness (SSF), measured in $\mathrm{mm}$. Lean body mass (LBM) was determined from SSF and total body weight using regression equations. ${ }^{3132}$ Body mass index (weight/height ${ }^{2}$, BMI) was also calculated. Cardiopulmonary fitness was quantified as maximum oxygen uptake $\left(\mathrm{VO}_{2}\right.$-max), using a standard running test on a treadmill. ${ }^{33} \mathrm{VO}_{2}$-max was expressed in $\mathrm{ml} . \mathrm{min}^{-1} \cdot \mathrm{kg}^{-2 / 3}$.

\section{LIFESTYLE PARAMETERS}

Habitual food intake was measured by a modification of the cross check dietary history interview, which was specially developed for the Amsterdam growth and health study. ${ }^{34}$ In this dietary history, the subjects were asked to recall their usual food intake (frequency, amounts as well as the methods of preparation) during the previous month. From this information food characteristics were calculated with the Dutch food and nutrition table. ${ }^{35}$ The following food characteristics were assessed:

(1) Energy intake relative to body weight (kcal/ $\mathrm{kg}$ ),

(2) The intake of saturated fatty acids, expressed as a percentage of total energy intake, and

(3) Cholesterol intake relative to total energy intake.

At the same dietary interview, the total amount of consumed alcohol (expressed in grams) was assessed.

Daily physical activity was measured with a structured interview covering the three months before the interview. It was expressed in a total weighted activity score, which combines both the duration and intensity of daily physical activities during work, school, sport, transportation, and leisure time. ${ }^{36}$ The weighted score was expressed in METs/week. Regular smoking behaviour (expressed in grams of tobacco smoked per week) was determined by questionnaire at the time of each measurement.

Extensive information about the methods used in the Amsterdam growth and health study has been given by Kemper. ${ }^{37} 38$

\section{ANALYSIS}

The statistical model which was used to assess the relation between the longitudinal development of TC, HDL, and the TC/HDL ratio on the one hand and biological parameters on the other hand, correcting for certain lifestyle parameters, is explained in the Appendix. The parameters of the model were estimated with generalised estimating equations (GEE) ${ }^{39}$

In the presented study three statistical analyses were carried out:

(1) A "univariate" analysis, in which the longitudinal developments of TC, HDL, and the TC/HDL ratio were related to the development of each of the biological parameters separately, correcting only for gender, time, and biological age, 
Table 1 Mean (SD) of total serum cholesterol (TC), high density lipoprotein cholesterol (HDL), and the TC/HDL ratio in relation to calendar age and gender

\begin{tabular}{|c|c|c|c|c|c|c|}
\hline \multirow{2}{*}{$\begin{array}{l}\text { Calender } \\
\text { age }(y)\end{array}$} & \multicolumn{2}{|c|}{$T C(\mathrm{mmol} / \mathrm{l})$} & \multicolumn{2}{|c|}{$H D L(\mathrm{mmol} / \mathrm{l})$} & \multicolumn{2}{|l|}{$T C / H D L$} \\
\hline & $\delta$ & q & $\delta$ & $q$ & $\delta$ & $q$ \\
\hline $\begin{array}{l}13 \\
14 \\
15 \\
16 \\
21 \\
27\end{array}$ & $\begin{array}{l}4.5(0.6) \\
4.3(0.7) \\
4.1(0.7) \\
4.0(0.6) \\
4.5(0.8) \\
5.0(0.9)\end{array}$ & $\begin{array}{l}4.4(0.7) \\
4.4(0.7) \\
4.4(0.7) \\
4.4(0.7) \\
4.9(0.7) \\
5.3(0.9)\end{array}$ & $\begin{array}{l}1.5(0.3) \\
1.4(0.3) \\
1.3(0.2) \\
1.3(0.2) \\
1.2(0.2) \\
1.2(0.2)\end{array}$ & $\begin{array}{l}1.4(0.3) \\
1.4(0.3) \\
1.3(0.3) \\
1.4(0.3) \\
1.4(0.3) \\
1.6(0.4)\end{array}$ & $\begin{array}{l}3.1(0.6) \\
3.1(0.7) \\
3.4(0.8) \\
3.1(0.6) \\
4.0(0.9) \\
4.3(1.1)\end{array}$ & $\begin{array}{l}3.2(0.7) \\
3.2(0.7) \\
3.4(0.7) \\
3.2(0.8) \\
3.6(0.8) \\
3.3(0.8)\end{array}$ \\
\hline
\end{tabular}

Table 2 Mean (SD) of biological parameters lean body mass (LBM), sum of four skinfolds (SSF), and maximal oxygen uptake ( $\mathrm{VO}_{2}$-max) in relation to calender age and gender

\begin{tabular}{|c|c|c|c|c|c|c|}
\hline \multirow{2}{*}{$\begin{array}{l}\text { Calender } \\
\text { age }(y)\end{array}$} & \multicolumn{2}{|l|}{$L B M(\mathrm{~kg})$} & \multicolumn{2}{|l|}{$S S F(\mathrm{~mm})$} & \multicolumn{2}{|c|}{$\mathrm{VO}_{2}-\max \left(\mathrm{ml} \mathrm{min}^{-1} \cdot \mathrm{kg}^{-2 / 3}\right)$} \\
\hline & $\delta$ & q & $\sigma$ & $q$ & $\sigma^{*}$ & $q$ \\
\hline $\begin{array}{l}13 \\
14 \\
15 \\
16 \\
21 \\
27\end{array}$ & $\begin{array}{l}37.6(5.5) \\
43.5(6.1) \\
48.4(6.0) \\
52.1(5.7) \\
60.9(5.8) \\
64.5(6.0)\end{array}$ & $\begin{array}{l}36.5(4.8) \\
38.9(4.6) \\
40.6(4.3) \\
41.7(4.4) \\
45.1(4.8) \\
47.5(4.9)\end{array}$ & $\begin{array}{l}28.4(10.9) \\
27.8(10.7) \\
27.8(10.3) \\
29.1(9.7) \\
34.9(11.9) \\
36.5(13.5)\end{array}$ & $\begin{array}{l}37.5(12.8) \\
40.0(13.8) \\
43.5(14.2) \\
45.8(14.6) \\
52.3(16.9) \\
46.3(16.5)\end{array}$ & $\begin{array}{l}21.0(1.8) \\
22.0(2.2) \\
22.5(1.7) \\
23.2(2.2) \\
22.3(2.4) \\
21.2(2.2)\end{array}$ & $\begin{array}{l}18.5(1.8) \\
18.7(1.7) \\
17.9(1.6) \\
17.9(1.5) \\
16.3(1.6) \\
16.1(2.0)\end{array}$ \\
\hline
\end{tabular}

Table 3 Standardised regression coefficients $(\beta)$ (95\% confidence intervals) according to univariate and multivariate analysis regarding the longitudinal development of total serum cholesterol (TC), high density lipoprotein cholesterol (HDL), and the TC/HDL ratio and the longitudinal development of lean body mass (LBM), sum of four skinfolds $(S S F)$, and maximal oxygen uptake $\left(\mathrm{VO}_{2}-\max \right) t$

\begin{tabular}{|c|c|c|c|c|}
\hline & & $T C$ & $H D L$ & $T C / H D L$ \\
\hline & & $\beta$ & $\beta$ & $\beta$ \\
\hline \multicolumn{5}{|c|}{ Univariate analysis } \\
\hline LBM & $\delta / q$ & $\begin{array}{l}-0.25^{* *} \\
(-0.33,-0.16)\end{array}$ & $-0.26^{* *}$ & $\begin{array}{l}0.04 \\
(-0.05 .013)\end{array}$ \\
\hline \multirow[t]{3}{*}{ SSF } & $\delta$ & $0.29^{* *}$ & & $0.41^{* *}$ \\
\hline & & $(0.17,0.41)$ & $-0.10^{* *}$ & $(0.24,0.58)$ \\
\hline & $q$ & $\begin{array}{l}0.14^{* *} \\
(0.05,0.23)\end{array}$ & $(-0.18,-0.03)$ & $\begin{array}{l}0.15^{* *} \\
(0.04,0.26)\end{array}$ \\
\hline $\mathrm{VO}_{2}-\mathrm{max}$ & $\delta / 9$ & $-0.10^{*}$ & $0.08^{*}$ & $-0.17^{* *}$ \\
\hline \multicolumn{5}{|c|}{ Multivariate analysisf } \\
\hline LBM & $\delta / 9$ & $\begin{array}{l}-0.27^{* *} \\
(-0.35,0.19)\end{array}$ & $-0.28^{* *}$ & $\begin{array}{l}0.03 \\
(-0.05,0.11)\end{array}$ \\
\hline \multirow[t]{3}{*}{ SSF } & $\delta$ & $0.32^{* *}$ & $(-0.51,-0.10)$ & $0.41^{* *}$ \\
\hline & & $(0.18,0.46)$ & -0.06 & $(0.23,0.59)$ \\
\hline & q & $\begin{array}{l}0.17^{* *} \\
(0.11,0.23)\end{array}$ & $(-0.13$ to 0.02$)$ & $\begin{array}{c}0.15^{* *} \\
(0.04,0.26)\end{array}$ \\
\hline $\mathrm{VO}_{2}-\max$ & $\delta / 9$ & -0.00 & $0.11^{* *}$ & $-0.11^{*}$ \\
\hline \multicolumn{5}{|c|}{ Multivariate analysis $₫$} \\
\hline LBM & $8 / 9$ & $\begin{array}{l}-0.27^{* *} \\
(-0.35-0.19)\end{array}$ & $\begin{array}{l}-0.26^{* *} \\
(-0.36-0.17)\end{array}$ & $\begin{array}{l}0.01 \\
(-0.0709)\end{array}$ \\
\hline \multirow[t]{2}{*}{ SSF } & o & $0.32^{* *}$ & & $0.39^{* *}$ \\
\hline & q & $\begin{array}{l}(0.18,0.46) \\
0.15^{* *} \\
(0.06,0.24)\end{array}$ & $\begin{array}{l}-0.04 \\
(-0.11 \text { to } 0.03)\end{array}$ & $\begin{array}{l}(0.25,0.53) \\
0.13^{* *} \\
(0.04,0.22)\end{array}$ \\
\hline $\mathrm{VO}_{2}-\max$ & $\delta / q$ & $\begin{array}{l}-0.01 \\
(-0.10,0.07)\end{array}$ & $\begin{array}{l}0.08^{*} \\
(0.01 \text { to } 0.16)\end{array}$ & $\begin{array}{l}-0.09^{*} \\
(-0.18,-0.00)\end{array}$ \\
\hline
\end{tabular}

${ }^{*} \mathrm{p}<0.05 ;{ }^{* *} \mathrm{p}<0.01$.

+ When no significant interaction was found with gender, only one coefficient was calculated for males and females.

$\ddagger$ Correcting for biological parameters

$\S$ Correcting for biological and lifestyle paramteters.

(2) A multivariate analysis in which the developments of TC, HDL, and the TC/HDL ratio were related to each of the biological parameters, correcting for the other biological parameters, gender, time, and biological age, and

(3) A multivariate analysis, in which the longitudinal development was related to each of the biological parameters, not only correcting for the other biological parameters, gender, time and biological age, but also for the lifestyle parameters.

After assessing the main effects, for each of the biological parameters, an interaction term with gender was added to the statistical model.
When a significant interaction was found between one of the biological parameters and gender, separate coefficients were calculated for males and females. In addition, interactions between time and each of the biological parameters were added to the model in order to investigate if the relations between lipoprotein levels and biological parameters were stronger at the beginning (adolescence) or at the end of the longitudinal period. The interaction terms were formed by multiplication of the two parameters involved.

All GEE analyses were carried out with the Statistical Package for Interactive Data Analysis (SPIDA). ${ }^{40}$

\section{Results}

Descriptive data on TC, HDL, and the TC/ HDL ratio are shown in table 1 . Mean values are given for males and females for each of the six measurements. In table 2 similar descriptive information is given for the biological parameters LBM, SSF, and $\mathrm{VO}_{2}$-max.

The results of the longitudinal GEE analysis regarding the longitudinal relation between TC, HDL, and the TC/HDL ratio on one hand and the biological parameters SSF, LBM, and $\mathrm{VO}_{2}$-max on the other are shown in table 3 . In the univariate analysis all relations were significant except for the relation between LBM and the $\mathrm{TC} / \mathrm{HDL}$ ratio. Correcting for the other biological parameters (the first multivariate analysis) and correcting for the lifestyle parameters (the second multivariate analysis) made some of these relations - the inverse relation between $\mathrm{VO}_{2}-\max$ and $\mathrm{TC}$ and the inverse relation between SSF and HDL - disappear. The results of the final multivariate analysis showed that LBM was inversely related to both TC and HDL. SSF was positively related to $\mathrm{TC}$ and the $\mathrm{TC} / \mathrm{HDL}$ ratio. Both relations were stronger for males than for females. $\mathrm{VO}_{2}$-max was positively related to $\mathrm{HDL}$ and negatively to the TC/HDL ratio. With regard to TC, a positive interaction $(\mathrm{p} \leq 0.05)$ was found between SSF and time and between LBM and time, indicating that the relation with SSF was stronger at the end of the longitudinal period and the relation with LBM was stronger at the beginning of the longitudinal period. With regard to the TC/HDL ratio, there was a strong negative interaction $(\mathrm{p} \leq 0.01)$ between $\mathrm{VO}_{2}$-max and time, also indicating a stronger relation at the end of the longitudinal period. Because BMI is most frequently used as a indicator for body fatness, the longitudinal relation between BMI and the lipoproteins was also analysed. The correlation matrix between SSF, LBM, and BMI (table 4) showed that BMI was closely related to both SSF and LBM. Therefore in the multivariate analyses only a correction for $\mathrm{VO}_{2}$-max was made. The results showed that the development of BMI was positively related to the development of TC, negatively to the development of $\mathrm{HDL}$, and positively to the development of the TC/HDL ratio in both univariate and multivariate analyses (table 5). In the relationship with TC, a strong positive interaction with time was found $(\mathrm{p} \leq 0.01)$. 
Table 4 Pearson correlation matrix of lean body mass (LBM), sum of four skinfolds (SSF), and body mass index (BMI) for males and females at each of the six longitudinal measurements

\begin{tabular}{|c|c|c|c|c|c|c|}
\hline \multirow[t]{2}{*}{$\mathrm{Age}(y)$} & \multicolumn{2}{|c|}{$L B M / S S F$} & \multicolumn{2}{|c|}{$L B M / B M I$} & \multicolumn{2}{|c|}{$S S F / B M I$} \\
\hline & $\sigma$ & $q$ & 0 & q & $\sigma$ & $q$ \\
\hline $\begin{array}{l}13 \\
14 \\
15 \\
16 \\
21 \\
27\end{array}$ & $\begin{array}{r}0.13 \\
0.15 \\
0.22 \\
0.08 \\
-0.13 \\
0.06\end{array}$ & $\begin{array}{l}0.38^{*} \\
0.31^{*} \\
0.32^{*} \\
0.23 \\
0.15 \\
0.03\end{array}$ & $\begin{array}{l}0.66^{*} \\
0.65^{*} \\
0.66^{*} \\
0.61^{*} \\
0.55^{*} \\
0.57^{*}\end{array}$ & $\begin{array}{l}0.70^{*} \\
0.68^{*} \\
0.66^{*} \\
0.65^{*} \\
0.59^{*} \\
0.51^{*}\end{array}$ & $\begin{array}{l}0.62^{*} \\
0.67^{*} \\
0.68^{*} \\
0.58^{*} \\
0.46^{*} \\
0.60^{*}\end{array}$ & $\begin{array}{l}0.79^{*} \\
0.78^{*} \\
0.78^{*} \\
0.74^{*} \\
0.74^{*} \\
0.73^{*}\end{array}$ \\
\hline
\end{tabular}

${ }^{*} \mathrm{p}<0.01$.

Table 5 Standardised regression coefficient ( $\beta$ ) (95\% confidence intervals) according to univariate and multivariate analysis regarding the longitudinal development of total serum cholesterol (TC), high density lipoprotein cholesterol (HDL), and the TC/HDL ratio and the longitudinal development of body mass index (BMI) $t$

\begin{tabular}{|c|c|c|c|}
\hline & $T C$ & $H D L$ & $T C / H D L$ \\
\hline & $\beta$ & $\beta$ & $\beta$ \\
\hline \multicolumn{4}{|l|}{ Univariate analysis } \\
\hline$\delta$ & $\begin{array}{l}0.10^{* *} \\
(0.03 \text { to } 0.17)\end{array}$ & $\begin{array}{l}-0.23^{* *} \\
(-0.35,-0.13) \\
-0.07 \\
(-0.17,0.04)\end{array}$ & $\begin{array}{l}0.37^{* *} \\
(0.23,0.50) \\
0.11^{* *} \\
(0.04,0.19)\end{array}$ \\
\hline \multicolumn{4}{|l|}{ Multivariate analysis $\ddagger$} \\
\hline 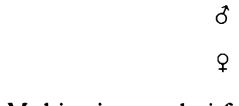 & $\begin{array}{l}0.09^{*} \\
(0.02 \text { to } 0.17)\end{array}$ & $\begin{array}{l}-0.23 * * \\
(-0.35,0.13) \\
-0.08 \\
(-0.18,0.03)\end{array}$ & $\begin{array}{l}0.36^{* *} \\
(0.22,0.49) \\
0.11^{* *} \\
(0.04,0.19)\end{array}$ \\
\hline \multicolumn{4}{|l|}{ Multivariate analysis $\$$} \\
\hline$\delta$ & $\begin{array}{l}0.09^{*} \\
(0.01 \text { to } 0.17)\end{array}$ & $\begin{array}{l}-0.21 * * \\
(-0.33,-0.09) \\
-0.05 \\
(-0.14,0.04)\end{array}$ & $\begin{array}{l}0.34^{* *} \\
(0.21,0.48) \\
0.09^{*} \\
(0.01,0.18)\end{array}$ \\
\hline
\end{tabular}

${ }^{*} \mathrm{p}<0.05 ;{ }^{* *} \mathrm{p}<0.01$

t When no significant interaction was found with gender, only one coefficient was calculated for males and females.

$\ddagger$ Correcting for $\mathrm{VO}_{2}$-max.

Correcting for $\mathrm{VO}_{2}$-max and lifestyle parameters.

\section{Discussion}

In this study the longitudinal relation was investigated between TC, HDL, and the TC/ HDL ratio and the biological parameters, SSF, $\mathrm{LBM}, \mathrm{VO}_{2}-\mathrm{max}$, and $\mathrm{BMI}$ over a period of 15 years in subjects aged from 13 to 27 years. The relation was investigated using all available longitudinal data and correcting for the lifestyle parameters: smoking behaviour, alcohol consumption, dietary intake, and daily physical activity. The statistical model used (equation 1 ), however, is certainly not the only way to analyse these longitudinal data. In the model presented here, for instance, $Y_{i t}$ is related to $X_{i t}$, while a time lag between the dependent and the independent variables could also be modelled (eg, relating $Y_{i t}$ to $\left.X_{i(t-1)}\right)$. Another possibility is to model changes in parameters between the different time points instead of the actual values. The results of this study should be interpreted with respect to the limitations of the statistical model used.

Before discussing our results it should be stated that these should be interpreted with some caution, because they were based on a study with a relatively small number of subjects (181). Furthermore, it should be remebered that it is difficult to compare our results with those of other studies, because we used a new method which combines cross sectional and longitudinal effects into one coefficient. To our knowledge, there are no longitudinal studies investigating the relation between lipoproteins and biological parameters which have used lon- gitudinal data analysing techniques like GEE.

Body fatness, operationalised as SSF, was highly positively related to TC and the TC/ HDL ratio. This relation was stronger for females than for males. The positive interaction between SSF and time regarding the relation with TC indicates that the relation between SSF and TC is stronger at the end of the longitudinal period than during adolescence.

Most studies investigating the relation between body fatness and lipoprotein values during adolescence and young adulthood have used BMI rather than SSF as an indicator of body fatness. In cross sectional studies, BMI was found to be positively associated with TC, inversely with HDL, and positively with the $\mathrm{TC} / \mathrm{HDL}$ ratio in both males and females, ${ }^{716-19}$ which is comparable to our results. In the study of Garn et $a l^{10}$ body fatness was, as in our study, quantified as SSF. They found a positive relation between skinfold thickness and TC among boys and girls from 15 to 19 years old. Kikuchi et a ${ }^{20}$ used subscapular skinfold thickness as indicator for body fatness and they found a negative relation between skinfold thickness and HDL.

There are only a few longitudinal studies investigating the relation between a change in body fatness and a change in lipoprotein levels during adolescence and young adulthood. In the Bogalusa heart study, ${ }^{9}$ a positive relation between a change in body fatness (body fatness quantified as triceps skinfold thickness) and a change in TC was found for boys, but not for girls. In addition to that a negative relation between a change in body fatness and a change in HDL was also found. The relation was investigated over a period of five years, with subjects aged between 5 and 12 years at the beginning of the study. In the Muscatine study, ${ }^{11}$ a change in body fatness (body fatness operationalised as BMI) over a period of 10 years was significantly related to TC in boys and girls with an initial age from 8 to 18 years. The relation between body fatness and TC probably results from an increased flow of free fatty acids to the liver, which is followed by an increased production of very low density lipoprotein, ie, higher values of TC. ${ }^{41}$

Thus, positive relations between body fatness and $\mathrm{TC}$ and the $\mathrm{TC} / \mathrm{HDL}$ ratio have been found in both cross sectional and longitudinal studies, which is equivalent to our results. In most studies, however, a negative relation between body fatness and HDL has been found, while in our study only in a univariate analysis was this relation found. The reason for this contradictory result is the fact that in the multivariate analyses the relation between body fatness (ie, the SSF) is analysed correcting for LBM, which seems to be related more to the development of HDL than SSF (table 3). LBM was not only negatively related to HDL, but also negatively to TC. With regard to the TC/ HDL ratio, often mentioned to be more important with respect to atherosclerosis than the single values of TC or HDL, ${ }^{23}$ there was no relation with LBM in our study.

As mentioned before, in most studies body fatness is quantified as BMI. BMI, however, 
not only reflects body fatness, but also LBM. This is shown in the correlation matrix between the SSF, LBM, and BMI at each of the six longitudinal measurements (table 4). From the correlation matrix along with the results of the longitudinal relations it can be concluded that the inverse relation between BMI and HDL probably reflects the relation between LBM and HDL, rather than the relation between body fatness (ie, SSF) and HDL, which is often suggested. The reason why LBM was inversely related to TC and HDL is not clear. Perhaps it has something to do with low plasma glucose and insulin concentrations, both of which are not only related to high LBM, but also to lower TC values. ${ }^{24}$

Cardiopulmonary fitness, represented in our study by $\mathrm{VO}_{2}$-max, was positively related to HDL and negatively to the TC/HDL ratio. This indicates that a higher $\mathrm{VO}_{2}-\mathrm{max}$ is related to a lower risk profile in terms of hypercholesterolaemia. There are many studies investigating the relation between lipoprotein levels and physical fitness. The results, however, are controversial. Dwyer et $a l^{2}$ studied children of 9,12 , and 15 years of age in the Australian schools health and fitness survey. They used the physical work capacity on a bicycle ergometer at a heart rate of 170 beats per minute $\left(\mathrm{PWC}_{170}\right)$ as the indicator for cardiopulmonary fitness and they did not find a cross sectional relation between fitness and TC and between fitness and HDL. Sallis et $a l^{12}$ and Armstrong et $a l,{ }^{15}$ however, did find a cross sectional relation in the same age groups between cardiopulmonary fitness (defined as $\mathrm{VO}_{2}-\mathrm{max}$ ) and TC, $\mathrm{HDL}$, and the TC/HDL ratio. But when they corrected their results for body fatness, the relationships disappeared. Hofman and Walter ${ }^{13}$ investigated the relation between physical fitness and lipoprotein levels longitudinally over a period of five years in boys and girls. The initial age of the boys and girls was 9 , and fitness was defined as a heart rate recovery index after a step test. They found a relation between the change in fitness and the change in HDL for boys, but not for girls. Dwyer et $a l,{ }^{8}$ on the other hand, did not find a relation between a change in fitness (determined as running time on a treadmill) and a change in HDL and the TC/HDL ratio among men aged 21 years over a period of nine weeks.

The differences in our results compared with others are partly due to the fact that in most studies the relation is investigated without correction for any lifestyle parameter. Only in the study of Dwyer et al was the relation investigated longitudinally, correcting for both lifestyle parameters and body fatness. However, these authors studied the relation over a time period of nine weeks, which is very short.

The fact that subjects with high cardiopulmonary fitness showed higher HDL levels (and therefore lower values of the TC/HDL ratio) is probably caused by an increased activity of lipoprotein lipase (LPL) and lecithin: cholesterol acyltransferase (LCAT). Both activities are increased by high levels of cardiopulmonary work and both are known to increase the concentration of HDL. ${ }^{424}$ This effect is irrespective of the effect of body fatness, because the amount of body fatness is not associated with LPL activity. ${ }^{42}$

In this study a comparison was made between univariate analyses, in which each of the biological parameters was analysed separately correcting for time, gender, and biological age, and multivariate analyses in which the biological parameters were analysed correcting for each other and correcting for lifestyle parameters. The most striking result of this comparison was the fact that in a multivariate analysis body fatness (ie, SSF) was not related to HDL, which was the case in the univariate analysis and which was also reported in many other studies.

In addition to the comparison between univariate and multivariate analyses, the impact of the control for lifestyle parameters could also be assessed. Comparison of the two multivariate analyses revealed that the influence of the adjustment for lifestyle parameters is only obvious in the longitudinal relation between $\mathrm{VO}_{2}$-max and HDL and the TC/HDL ratio. With correction for lifestyle parameters the standardised regression coefficient for $\mathrm{VO}_{2}-$ max in relation to HDL was 0.09 , and in relation to the $\mathrm{TC} / \mathrm{HDL}$ ratio it was 0.08 . Without adjustment, these coefficients were both 0.11 . So without the adjustment for lifestyle parameters the coefficients for $\mathrm{VO}_{2}$-max were overestimated more than $20 \%$. The fact that all other standardised regression coefficients were not or only slightly influenced by the adjustment for lifestyle parameters indicates that the correction for other biological parameters is more important then the correction for lifestyle parameters.

Although this study is quite complete with regard to the inclusion of both biological and lifestyle parameters, there are also potential confounding parameters which were not taken into account. Parameters like the use of oral contraceptives, pregnancy, and breastfeeding are parameters which could be related to body fatness as well as to the lipoprotein levels. Perhaps the lack of controlling for these gender specific parameters helps to explain the relatively low regression coefficients found for females compared with males in terms of the longitudinal relation between SSF and TC and the TC/HDL ratio.

\section{CONCLUSIONS}

From 13 to 27 years of age, body fatness was positively related to TC and the TC/HDL ratio. Thus, body fatness is related to a high risk profile with regard to hypercholesterolaemia. No relations were found between body fatness (ie, SSF) and HDL, which contradicts published findings. The unexpected results probably arose because of lack of correcting for confounding variables in most studies and the use of BMI as indicator for body fatness. BMI not only reflects body fatness, but also LBM, which was found to be inversely related to HDL. Cardiopulmonary fitness was related to a positive risk profile in respect of hypercholesterolaemia, as indicated by the positive 
longitudinal relation between $\mathrm{VO}_{2}$-max and HDL and the inverse relation with the TC/ $\mathrm{HDL}$ ratio. $\mathrm{VO}_{2}-\mathrm{max}$ was not related to $\mathrm{TC}$. In the longitudinal relation between lipoprotein levels and biological parameters, the adjustment for other biological parameters seemed to be more important than the correction for lifestyle parameters.

\section{Appendix}

To analyse the longitudinal relations the following statistical model was used:

$$
Y_{i t}=\beta_{0}+\sum_{j=1}^{\mathcal{J}} \beta_{1 j} X_{i j t}+\sum_{k=1}^{K} \beta_{2 k} Z_{i k t}+\beta_{3} t+\sum_{m=1}^{M} \beta_{4 m} G_{i m}+\varepsilon_{i t},
$$

where: $\mathrm{Y}_{i t}=$ observations of subject $i$ at time $t ; \beta_{0}=$ intercept; $\mathrm{X}_{i j t}=$ independent variable of interest $j$ of subject $i$ at time $t ; \beta_{1 j}$ regression coefficient of independent variable of interest $j ; \mathrm{J}=$ number of independent variables; $Z_{i k t}=$ time dependent covariate $k$ of subject $i$ at time $t ; \beta_{2 k}=$ regression coefficient of time dependent covariate $k ; \mathrm{K}=$ number of time dependent covariates; $t=$ time; $\beta_{3}=$ regression coefficient of time; $\mathrm{G}_{i m}=$ time independent covariate $m$ of subject $i ; \beta_{4 m}=$ regression coefficient of time independent covariate $m ; M=$ number of time independent covariates; and $\varepsilon_{i t}=$ measurement error of subject $i$ at time $t$.

In this model the coefficients of interest are $\beta_{1 j}$, because these standardised regression coefficients reflect the magnitude of the relation between the longitudinal development of the lipoprotein levels $\left(Y_{i t}\right)$ and the development of the different biological parameters of interest ie, SSF, LBM, $\mathrm{VO}_{2}$-max, and BMI $\left(X_{i j t}\right)$. This relation (between $Y_{i t}$ and $X_{i j t}$ ) is not only analysed under correction of time $(t)$, but also under correction of time dependent covariates $\left(Z_{i k t}\right)$ and time independent covariates $\left(G_{i m}\right)$. The lifestyle parameters (ie, total energy intake, the intake of saturated fatty acids, cholesterol intake, smoking, alcohol consumption, and the amount of daily physical activity) are also added to the model as time dependent covariates. Another time dependent covariate is biological age, whereas gender $\left(G_{i}\right)$ is the only time independent covariate in the model.

The parameters of the statistical model are estimated with generalised estimating equations (GEE). ${ }^{39}$ With GEE, the relations between the variables of the model at different time points (ie from $t_{1}$ to $t_{6}$ ) are tested simultaneously. In the model, both the dependent variables $\left(Y_{i t}\right)$ and the independent variables of interest $\left(X_{i j t}\right)$ were transformed into $z$-scores to abolish scale differences between the variables. Thus, as a result of the GEE analysis for each biological parameter of interest $\left(X_{i j}\right)$, an adjusted standardised regression coefficient was calculated $\left(\beta_{1 j}\right.$ 's), which can be interpreted as an adjusted longitudinal correlation coefficient.

The estimated $\beta_{1 j}$ 's reflect the relation between the longitudinal development of TC, HDL, or the TC/HDL ratio and the development of the corresponding biological parameter, with the development measured over a period of 15 years using all available longitudinal data at the six time points. With GEE analysis a pooled analysis of cross sectional and longitudinal relations is carried out. This means that the standardised regression coefficient $\beta_{1 j}$ combines the within subjects (ie, longitudinal) effects with the between subjects (ie, cross sectional) effects into one coefficient.

Because the repeated observations within one subject are not independent of each other, in GEE analysis, a correction is made for the within subject correlations. This correction is carried out by assuming a priori a certain correlation structure for the repeated measurements of the dependent variable (ie, the lipoprotein measurements). First of all, an independent structure can be considered. In this structure all within subject correlations are assumed to be zero. However, the within subject correlations in the data set under consideration are far from zero. The lowest Pearson correlation coefficient between two longitudinal measurements for TC, for instance, is around 0.5. Secondly, an exchangeable correlation structure can be considered. In this structure all correlations are assumed to be equal, irrespective of the time period under consideration. In addition, this structure is not suitable for the data set of the Amsterdam growth and health study. This is because the total time period under consideration is quite long. For instance for TC, the Pearson correlation coefficients between two longitudinal measurements vary between 0.5 and 0.8 . The third possible structure is a stationary $m$-dependent structure, which means that correlations $k$ measurements apart are the same for $k=1, . ., m$, while the within subject correlations between measurements more than $m$ occasions apart are assumed to be zero. Because of the high values of the within subject correlations and the fact that the within subject correlations vary between the different interperiods, a 5dependent correlation structure is assumed to be the best estimate of the "real" correlation structure for TC, HDL, as well as the TC/ HDL ratio. Therefore all GEE analyses are carried out with this a priori assumed correlation structure. This study was granted by the Dutch Heart Foundation (grant
no $76051-79051$ and $90-312$ ), the Dutch Prevention Fund no 76051-79051 and 90-312), the Dutch Prevention Fund (grant no 28-189 of $^{\mathrm{a}}$ 28-1106 and 28-1106-1), the Dutch Ministry of Well Being and Public Health (grant no

Dairy Foundation on Nutrition and Health.
The authors wish to thank Dr G B Post, who collected the nutritional data.

1 Montoye HJ. Risk indicators for cardiovascular disease in relation to physical activity in youth. In: Brinkhorst RA,
Kemper HCG, Saris WHM, eds. Children and exercise XI, Kemper HCG, Saris WHM, eds. Children and exercise XI,
International Series on Sport Sciences, vol 15. Champaign: International Series on Sport Scien

2 Wallace RB, Anderson RA. Blood lipids, lipid related measures, and the risk of atherosclerotic cardiovascular disease. ures, and the risk of atheroscler.tiol Rev 1987;9:95-119.

3 Manson JE, Tosteson H, Ridker PM, et al. The primary prevention of myocardial infarction. N Eng $\mathcal{F}$ Med 1992; 326:1406-16.

4 Kemper HCG, Snel J, Verschuur R, Storm-van Essen L. Tracking of health and risk indicators of cardiovascular diseases from teenager to adult - Amsterdam growth and health study. Prev Med 1990;19:642-55.

5 Porkka KVK, Viikari JSA, Åkerblom HK. Tracking of serum HDL-cholesterol and other lipids in children and adolescents. The cardiovascular risk in young finns study. Prev Med 1991;20:713-24.

6 Guo S, Becket L, Chumlea WC, Roche AF, Siervogel RM. 
Serial analysis of plasma lipids and lipoproteins from individuals 9-21 y of age. Am 7 Clin Nutr 1993;58:61-7.

7 Garrison RJ, Wilson PW, Castelli WP, Feinleib M, Kanne WB, McNamara PM. Obesity and lipoprotein cholesterol in the Framingham offspring study. Metabolism 1980;29: $1053-60$.

8 Dwyer T, Calvert GD, Baghurst KL, Leitch DR. Diet, other lifestyle factors and HDL cholesterol in a population of Australian male service recruits. Am $\mathcal{f}$ Epidemiol 1981; 114:683-96.

9 Freedman DS, Burke GL, Harsha DW, et al. Relationship of changes in obesity to serum lipid and lipoprotein changes in childhood and adolescence. $\mathcal{F} A M A$ 1985;254 115-20.

10 Garn SM, Sullivan TV, Hawthorne VM. Effect of skinfold levels on lipids and blood pressure in younger and older adults. F Gerontology 1988;43:M170-4.

11 Lauer RM, Lee J, Clarke WR. Factors affecting the relationship between childhood and adult cholesterol levels: The Muscatine study. Pediatrics 1988;82:309-18.

12 Sallis JF, Patterson TL, Buono MJ, Nader PR. Relation of cardiovascular fitness and physical activity to cardio-
vascular disease risk factors in children and adults. $A m \mathcal{F}$ vascular disease risk factors in

13 Hofman A, Walter HJ. The association between physical fitness and cardiovascular disease risk factors in children in a five-year follow-up study. Int $\mathcal{F}$ Epidemiol 1989;18: $830-5$.

14 Faber M, Spinnler-Benadé AJ, Daubitzer A. Dietary intake, anthropometric measurements and plasma lipid levels in
throwing field athletes. Int $\mathcal{F}$ Sports Med 1990;11:140-5.

15 Armstrong N, Williams J, Balding J, Gentle P, Kirby B. Cardiopulmonary fitness, physical activity patterns, and selected coronary risk factor variables in 11- to 16-yearolds. Ped Exer Sci 1991;3:219-28.

16 Van Horn LV, Ballew C, Liu K, et al. Diet, body size and plasma lipids-lipoproteins in young adults: Differences by plasma lipids-lipoproteins in young adults: Differences by
race and sex. The coronary artery risk development in young adults (CARDIA) study. Am f Epidemiol 1991;133: young

17 Marti B, Tuomilehto J, Salomaa V, Kartovaara L, Korhonen HJ, Pietinen P. Body fat distribution in the Finish population: environmental determinants and predictive power for cardiovascular risk factor levels. $\mathcal{F}$ Epidemiol Community Health 1991;45:131-7.

18 Wattigney WA, Harsha DW, Srinivasan SR, Webber LS, Berenson GS. Increasing impact of obesity on serum lipids and lipoproteins in young adults. The Bogalusa heart study. Arch Intern Med 1991;151:017-22.

19 Bonora E, Zenere M, Branzi P, et al. Influence of body fat and its regional localization on risk factors for atherosclerosis in young men. Am $\mathcal{F}$ Epidemiol 1992;135:1271-8.

20 Kikuchi DA, Srinivasan SR, Harsha DW, Webber LS, Sellers TA, Berenson GS. Relation of serum lipoprotein lipids TA, Berenson GS. Relation of serum lipoprotein lipids
and alipoproteins to obesity in children: The Bogalusa and alipoproteins to obesity in childre

21 Reeder BA, Angel A, Ledoux M, Rabkin SW, Toung TK, Sweet LE. Obesity and its relation to cardiovascular disease risk factors in Canadian adults. Can Med Assoc $\mathcal{F}$ 1992;146:2009-19.

22 Dwyer T, Gibbons LE. The Australian schools health and fitness survey. Physical fitness related to blood pressure but not lipoproteins. Circulation 1994;89:1539-44.

23 Goldberg L, Elliot DL, Schutz RW, Kloster FE. Changes in lipid and lipoproteins levels after weight training. $\mathscr{F} A M A$ 1984;252:104-6.
24 Yki-Järvinen $H$, Koivisto VA, Taskinen M-R, Nikkilä EA. Glucose tolerance, plasma lipoproteins and tissue lipoprotein lipase activities in body builders. Eur 7 Appl Physiol 1984;53:253-9.

25 Twisk JWR, Kemper HCG, Mellenbergh GJ. Longitudinal development of lipoprotein levels in males and females between 12-28 years of age: The Amsterdam growth and health study. Int $\mathcal{f}$ Epidemiol 1995;24:69-77.

26 Abell LL, Levy BB, Brody BB, Kendall FE. Simplified method for the estimation of total cholesterol in serum method for the estimation of total cholesterol in serum and demons

27 Huang TC, Chen CP, Wefler V, Raftery A. A stable reagen for the Lieberman Buchard reaction: application to rapid serum cholesterol determination. Analyt Chem 1961;33 1405-7.

28 Burstein M, Samaille J. Sur un dosage rapide du cholesterol lié aux-alpha-et aux bétalipoprotéines du serum. Clinica Chim Acta 1960;5:609.

29 Berenson GS, Srinivasan SR, Cresanta JL, Foster TA, Webber LS. Dynamic changes of serum lipoproteins in children during adolescence and sexual maturation. $\mathrm{Am}$ children during adolescence

30 Tanner JM, Whitehouse RH, Marshall WA, Healy MJR Goldstein H. Assessment of skeletal maturity and prediction of adult height (TW 2 method). London: Academic Press, 1975.

31 Durnin JVGA, Rahaman MM. The assessment of the amount of fat in human body measurements of skinfold thickness. Br f Nutr 1967;21:681-9.

32 Durnin JVGA, Womersley J. Body Fat assessed from total body density and its estimation from skinfold thickness: Measurement on 481 men and women aged from 16-72 years. Br f Nutr 1974;32:77-97.

33 Kemper HCG, Verschuur R. Maximal aerobic power in 13and 14-year old teenagers in relation to biological age. Int $¥$ Sports Med 1981;2:97-100.

34 Post GB. Nutrition in adolescence, a longitudinal study in dietary patterm from teenage to adult. Wageningen: Agricultural pattern from teenage to adult. Wageni

35 Dutch food and nutrition table (in Dutch). Stichting NEVO, Voorlichtingsburo voor de voeding. 1985.

36 Verschuur R. Daily physical activity and health. Longitudinal changes during the teenage period. Amsterdam: Universiteit van Amsterdam, 1987, Thesis.

37 Kemper HCG, ed. Growth, health and fitness of teenagers. Medicine and Sports Science. Vol 20. Basel: Karger, 1985

38 Kemper HCG, ed. The Amsterdam growth study: $A$ longitudinal analysis of health, fitness and lifestyle. HK Sport Science Monograph Series, Vol 6. Champaign: Human KinScience Monograph Series,

39 Zeger SL, Liang KY. Longitudinal data analysis for discrete and continuous outcomes. Biometrics 1986;42:121-30.

40 Gebski V, Leung O, McNeil D, Lunn D. SPIDA User manual, version 6. Eastwood, Australia: 1992.

41 Björntorp P. "Portal" adipose tissue as a generator of risk factors for cardiovascular disease and diabetes. $A r$ teriosclerosis 1990;10:493-6.

42 Nikkilä EA, Taskinen MR, Rehunen S, Härkönen M. Lipoprotein lipase activity in adipose tissue and skeletal muscle of runners: relation to serum lipoproteins. Metabolism 1978;27:1661-71.

43 Berg A, Frey I, Baumstark MW, Halle M, Keul J. Physica activity and lipoprotein lipid disorders. Sports Med 1994; 17:-21. 